\title{
IM HIMMEL DONNERN HELFEN. STATIONEN EINER WANDERANEKDOTE BEI PFEFFEL, BÜCHNER UND ANDEREN
}

\author{
HEINZ HÄRTL \\ In memoriam Kurt Krolop
}

\begin{abstract}
Helping to Thunder in Heaven. Stages of a "Wanderanekdote" in Pfeffel, Büchner, and others

Following renowned literary critic Kurt Krolop's two publications in 1960 and 1963, this analysis investigates the dissemination and variations of the topos "Helping Thundering in Heaven". Concurrently, attention is given to the "Wanderanekdote", that publicized the topos throughout German literary as well as cultural history from the 18th century to the present. A common element in most of them - and that is true for a prominent number of variations researched for the first time - is the change of a perspective of hope for a better beyond from "below" by disillusionment and the attention on the misery of our everyday life. The historicizing and systematizing investigation reconstructs the environment, in which highlights of representations of the topos emerge, such as Konrad Pfeffel's poem "Jost" (1789) and Georg Büchner's "Woyzeck"-fragments (1836).
\end{abstract}

Keywords: German, Literary History, Cultural History, topos, anecdote, Pfeffel, Jost, Büchner, Woyzeck

Wir arme Leut. Sehn sie, Herr Hauptmann, Geld, Geld. Wer kein Geld hat. Da setz einmal einer seinsgleichen auf die Moral in die Welt[.] Man hat auch sein Fleisch und Blut. Unsereins ist doch einmal unseelig in der und der andern Welt, ich glaub' wenn wir in Himmel kämen, so müßten wir donnern helfen. ${ }^{1}$

Sagt Woyzeck in den im Wesentlichen 1836 entstandenen unvollendeten Szenenfolgen Georg Büchners, die von Karl Emil Franzos (1848-1904) 1879 als „Wozzeck“ erstmals aus

1 Georg Büchner: Woyzeck. Marburger Ausgabe. Band 7.2. Text, Editionsbericht, Quellen, Erläuterungsteile. Hg. von Burghard Dedner unter Mitarbeit von Arnd Beise, Ingrid Rehme, Eva-Maria Vering und Manfred Wenzel. Darmstadt 2005 (Büchner: Sämtliche Werke und Schriften. Historischkritische Ausgabe mit Quellendokumentation und Kommentar. Hg. von Burghard Dedner, mitbegründet von Thomas Michael Mayer), S. 25. 
den schwer lesbaren Handschriften ediert wurden. Zum Verständnis der zitierten Passage hat Kurt Krolop in einer 1960 erschienenen Untersuchung grundlegend beigetragen, in der er den unmittelbaren Traditionsbezug des Topos vom Donnernhelfenmüssen darlegte. Gegen die 1934 publizierte Hypothese Rudolf Majuts, zu ihm könne Büchner von einer Stelle in Arnims „Kronenwächtern“ (1817) angeregt worden sein, ${ }^{2}$ führte Krolop „mit ziemlicher Sicherheit“ den Nachweis, dass Gottlieb Konrad Pfeffels 1789 erstmals veröffentlichtes Gedicht „Jost“ die Quelle war. ${ }^{3}$

In den „Kronenwächtern“ erwidert ein alter Bergmann einem Geistlichen, der ihm „Muth“ fürs Jenseits „einzusprechen“ sucht: „ihm würde im Himmel auch nichts geschenkt werden; er werde ta praw tonnern helfen müssen." 4

Der Bergmann ist als Abgesandter Luthers an Berthold, die Hauptfigur des Romans, ein tüchtiger und biederer, ${ }^{5}$ Gott vertrauender Lutheraner der ersten Stunde. Der Dialekt kennzeichnet seine thüringisch-sächsische Herkunft aus dem Ursprungsgebiet des neuen Glaubens. Er spricht als dessen Anhänger für sich, nicht auch für andere.

Anders im „Woyzeck“ - und bei Pfeffel:

Jost.
Von seinem milden Landesvater
Durch Frohnen abgezehrt, lag Jost
Auf faulem Moos. Ein frommer Pater
Gab in dem letzten Kampf ihm Trost:
Bald, sprach er, wird euch Gott entbinden
Vom Joch, das euch so hart gedrückt:
Die Ruhe, die euch nie beglückt,
Freund, werdet ihr im Himmel finden.
Ach, Herr! rief Jost so dumpf und hohl
Wie aus dem Grab, wer kann das wissen?
Wir armen Bauern werden wohl
Im Himmel frohnweis donnern müssen. ${ }^{6}$

Mit Woyzeck hat Jost im Unterschied zum Arnimschen Bergmann gemeinsam, dass sie ohne Gottvertrauen „auf der untersten Stufe der jeweiligen Gesellschaftspyramide“7 stehen. Jost vertritt den Bauernstand gegen die beiden oberen Stände, die als „Landesvater“ und „Pater“ im Reim zusammenkommen. Die ebenfalls gereimte ausgleichende

2 Rudolf Majut: Büchneriana. I. Büchner und Arnim. In: Germanisch-Romanische Monatsschrift 22, 1934, S. 481.

3 Kurt Krolop: Büchner und Pfeffel. In: Germanistica Pragensia 1, 1960 (Acta Unversitatis Carolinae. Philologica 3), S. 3-12, zit. S. 3.

4 [1. Titelseite:] Die Kronenwächter. Von L. Achim von Arnim. Erster Band. Berlin, 1817. In der Maurerschen Buchhandlung. [2. Titelseite:] Berthold's erstes und zweites Leben. Ein Roman, von Ludwig Achim von Arnim. Berlin, 1817. Maurersche Buchhandlung. Poststraße Nr. 29, S. 256.

5 Brav (praw): „von männern im sinne von tüchtig, tapfer, wacker, redlich“ (Deutsches Wörterbuch. Hg. von Jacob und Wilhelm Grimm [u.a.]. Leipzig 1854-1960. Reprint München 1984 (danach zitiert), Bd. 2 [1860], Sp. 339.

6 Poetische Versuche von Gottlieb Conrad Pfeffel, Hessen-Darmstädtischen[!] Hofrath, der Helvetischen Gesellschaft und der Königlich-Preussischen Akademie der Künste Mitgliede. Erster[-Dritter] Theil. Basel, bey Wilhelm Haas dem Sohne, 1789[-1790]. Darin: Zweyter Theil, 1789, S. 86.

7 Krolop: Büchner und Pfeffel (wie Anm. 3), S. 4f. 
Verheißung des Geistlichen, wer hienieden „gedrückt“ sei, werde im Jenseits „,beglückt“, stellt Jost in Frage: „wer kann das wissen?“ Woyzeck hinterfragt nicht mehr, er konstatiert ex negativo: „unseelig in der und der andern Welt“. Anders als Jost, der für die „armen Bauern“ spricht, spricht Woyzeck für alle Armen („Wir arme Leut“) gegen alle oberhalb der Armutsgrenze. Was er sagt, ist, verglichen mit dem, was Jost sagt, Krolop zufolge eine letztlich auf „die Auflösung der alten Ständeordnung“ zurückzuführende „Erweiterung und Steigerung“ der Gesellschaftssatire des Spätaufklärers Pfeffel durch den radikalen Vormärzautor Büchner. ${ }^{8}$

Pfeffels Gedicht steht noch nicht in der 1761 anonym publizierten Ausgabe seiner frühen „Poetischen Versuche“, 9 sondern erstmals in der ersten nichtanonymen gleichen Titels, in der es im Jahr des Beginns der Französischen Revolution veröffentlicht wurde. ${ }^{10}$ Diese Ausgabe erlebte von 1791 bis 1821 drei weitere Auflagen. ${ }^{11}$ Daneben gab es dem KVK (Karlsruher Virtueller Katalog) zufolge, der der bis 1850 dokumentierten druckgeschichtlichen Recherche zugrunde liegt, zwei vermutlich nicht autorisierte Editionen gleichen Titels ${ }^{12}$ sowie Nachdrucke und Kompilationen, die als „Neueste Gedichte“13 und „Gedichte"14 angeboten wurden. 1834 erschien in Straßburg und Colmar eine letzte Ausgabe der „Poetischen Versuche“ ${ }^{\text {15 }}$ und 1841 in Hildburghausen und Amsterdam eine

8 Ebd., S. 5.

9 Poetische Versuche in drey Büchern. Frankfurt am Mayn, bey Johann Gottlieb Garbe, 1761.

10 Vgl. Anm. 6.

11 Poetische Versuche von Gottlieb Conrad Pfeffel, Hessen-Darmstädtischen[!] Hofrath, der Helvetischen Gesellschaft und der Königlich-Preussischen Akademie der Künste Mitgliede. Erster[-Dritter] Theil. Dritte Auflage. Basel, bey Wilhelm Haas dem Sohne, 1791. Darin: Zweyter Theil, 1791, S. 86. - Poetische Versuche von Gottlieb Conrad Pfeffel, Hessen-Darmstädtischen[!] Hofrath, der Helvetischen Gesellschaft und der Königlich Preußischen Akademie der Künste und der freyen literarischen Gesellschaften des Ober- und Niederrheins Mitgliede. Erster[-Zehnter] Theil. Vierte rechtmäßige und vermehrte Auflage. Tübingen in der J. G. Cotta’schen Buchhandlung. 1802[-1810]. Darin: Dritter Theil, 1803, S. 34. - Poetische Versuche von Gottlieb Conrad Pfeffel. Erster[-Neunter] Theil. Fünfte rechtmäßige Auflage. Tübingen in der J. G. Cotta’schen Buchandlung. 1816[-1821]. Darin: Dritter Theil, 1817, S. 34.

12 [1. Titelblatt:] Sammlung der vorzüglichsten Werke deutscher Dichter und Prosaisten. XXI. [-XXIII.] Band. [2. Titelblatt:] Pfeffels Gedichte. I.[-III.] Theil. Wien bei F. A. Schræmbl. MDCCXCI [-MDCCXCII]. [3. Titelblatt:] Poetische Versuche von Gottlieb Conrad Pfeffel, Hessen-Darmstädtischem[!] Hofrathe, der Helvetischen Gesellschaft und der Königl.-Preussischen Akademie der Künste Mitgliede. I.[-III.] Theil. Wien. Gedruckt und verlegt bey F. A. Schrämbl 1791[-1792]. Darin: Zweyter Theil, 1792, S. 94. - Poetische Versuche, von Gottlieb Conrad Pfeffel, Hessen-Darmstädtischen[!] Hofrath, der Helvetischen Gesellschaft und der königl.-preußischen Akademie der Künste Mitgliede. Erster[-Dritter] Theil. Vierte, vermehrte und verbesserte Auflage. Frankfurt und Leipzig, 1796. Darin: Zweyter Theil, 1796, S. 56.

13 Neueste Gedichte von Konrad Gottlieb Pfeffel. Aarnheim[!] 1802. In der neuen gelehrten Buchhandlung. Ohne „Jost“.

14 [1. Titelseite:] Pfeffels Gedichte. Erster[-Dritter] Theil. Wien und Prag bey Franz Haas 1809[-1810]. [2. Titelseite:] Poetische Versuche von Gottlieb Conrad Pfeffel. Erster[-Dritter] Theil. Darin: Dritter Theil, 1810, S. 34 .

15 Poetische Versuche von Gottlieb Conrad Pfeffel. Vollständige Ausgabe in fünf Bänden. Erster[-Fünfter] Band. Colmar, in Commission bei J. B. Geng. Strasburg, in Commission bei F. C. Heitz, Schlauchgasse N. 3. 1834. 
Gesamtausgabe der „Poetischen Werke“16, die im Jahr der deutschen Märzrevolution eine zweite Auflage erreichte. ${ }^{17}$

$\mathrm{Zu}$ untersuchen, wie diese Ausgaben sich zueinander verhalten, könnte von einer philologisch ambitionierten Pfeffel-Forschung geleistet werden, deren Ansätze zu einer kritischen Edition der poetischen Werke des unterschätzten Autors ${ }^{18}$ weitergeführt werden sollten. Im vorliegenden Beitrag kommt es auf den Nachweis an, dass mit den verschiedenen Ausgaben von Pfeffels „Poetischen Versuchen“ das Gedicht „Jost“ und der Topos vom Donnernhelfenmüssen eine erhebliche Verbreitung über einen längeren Zeitraum und das elsässisch-oberrheinische Kerngebiet der Pfeffelschen Publikationen hinaus erreichten. In den kontrollierten Ausgaben erschien es insgesamt zehnmal zwischen 1789 und 1848. ${ }^{19}$ Das ist eine erstaunliche Zahl, die Annahmen, Pfeffel sei ein bald nach seinem Tod in Vergessenheit geratener Autor, nicht entspricht. Von besonderem rezeptionsgeschichtlichen Interesse ist die sowohl von der Pfeffel- als auch von der Büchner-Forschung übersehene, bei Geng in Straßburg und Heitz in Colmar „in Commission“ erschienene seltene Ausgabe der „Poetischen Versuche“ aus dem Jahr 1834 (vgl. Anm. 15). Der KVK weist sie lediglich zweimal in öffentlichen Bibliotheken nach (Universitätsbibliothek Mainz, Bibliothèques universitaires de Strasbourg). Im vorliegenden Beitrag wird „Jost“ nach einem in Privatbesitz befindlichen Exemplar des Druckes wiedergegeben.

Mit dem Nachweis des Straßburg-Colmarer Ausgabe gewinnt Krolops Quellenzuschreibung vollends Evidenz. In dieser Ausgabe wird Büchner, der sich von etwa Mitte März 1835 bis Anfang Oktober 1836 im Straßburger Exil aufhielt, das Gedicht kennengelernt haben. Er wird mit dem Straßburger Buchhändler und Buchdrucker Friedrich Carl (Frédéric-Charles) Heitz (1798-1867) bekannt geworden sein, der seit 1818 die renommierte väterliche Firma weiterführte und zudem elsässischer Regionalhistoriker war. Als im Frühjahr 1839 der Liegnitzer Pfarrer Otto Friedrich Wehrhan (1795-1860) Straßburg besuchte, lernte er die Heitz'sche Bibliothek kennen, „welche 6000 bis 7000 revolutionsgeschichtliche Bände und außerdem eine Menge höchst interessanter Original-Manuscripte

16 [1. Titelseite:] Familien-Bibliothek der Deutschen Classiker. Eine Anthologie in 100 Bänden. Zehnter[-Zwölfter] Band. Poetische Werke von G. C. Pfeffel. Erster[-Dritter] Theil. [2. Titelseite:] Familien-Bibliothek der Deutschen Classiker. Eine Anthologie in 100 Bänden. Zehnter[-Zwölfter] Band. Poetische Werke von G. C. Pfeffel. Erster[-Dritter] Theil. Mit Biographie und Porträt. Hildburghausen und Amsterdam. Druck und Verlag des Bibliographischen Instituts. 1841. Darin: Dritter Theil, 1841, S. 50 .

17 [1. Titelseite:] Familien-Bibliothek der Deutschen Classiker. Eine Anthologie in 2 Serien, jede zu 52 Bänden. Erste Serie. - Zehnter[-Zwölfter] Band. Poetische Werke von G. C. Pfeffel. Erster[-Dritter] Theil. [2. Titelseite:] Familien-Bibliothek der Deutschen Classiker. Eine Anthologie. Erste Serie. Zehnter[-Zwölfter] Band. Poetische Werke von G. C. Pfeffel. Erster[-Dritter] Theil. Mit Biographie und Porträt. Hildburghausen und Amsterdam. Druck und Verlag des Bibliographischen Instituts. 1848. Darin: Dritter Theil, 1848, S. 50.

18 Vgl. vor allem: Walter Lauterwasser: Gevatter „Fabler“ am Scheideweg - Die „Poetischen Versuche“ Gottlieb Konrad Pfeffels. In: Gottlieb Konrad Pfeffel. Satiriker und Philantrop (1736-1809). Eine Ausstellung der Badischen Landesbibliothek Karlsruhe in Zusammenarbeit mit der Stadt Colmar. Ausstellungskatalog hg. von der Badischen Landesbibliothek. Karlsruhe 1986, S. 37-57, bes. 37f.; Theodor Verweyen: „Rezeptionsgeschichte - eine Geschichte von Siegern? Unmaßgebliche Anmerkungen zu den poetischen Versuchen Gottlieb Konrad Pfeffels." In: Gottlieb Konrad Pfeffel (1736-1809). Signaturen der Spätaufklärung am Oberrhein. Hg. von Achim Auernhammer und Wilhelm Kühlmann. Freiburg i.Br.-Berlin-Wien 2010, S. 59-92, bes. 40 f.

19 Textidentisch mit Ausnahme der Divergenz „Bauern“-„Bauren“ im vorletzten Vers. 
enthält, eine reiche Fundgrube von Nachrichten über jene merkwürdige Zeit“. ${ }^{20}$ Der Bericht legt die Annahme nahe, Büchner dürfte in der Heitz'schen Bibliothek insbesondere für sein Revolutionsdrama „Dantons Tod“ fündig geworden sein. ${ }^{21}$ Dass er auch mit Heitz' Compagnon Johann Baptist (Jean-Baptiste) Geng (1783-1859?) bekannt wurde, der in Colmar als Buchhändler ein Lesekabinett unterhielt, ist ebenfalls wahrscheinlich. Von wem Heitz und Geng die Pfeffel-Ausgabe „in Commission“ genommen hatten und wer sie herausgab, bleibt zu ermitteln. Vermutlich waren die Verleger auch die Herausgeber.

Dass Büchner während und nach seiner Straßburger Zeit Pfeffel-Gedichte gegenwärtig hatte, belegt eine zuerst von Fritz Bergemann, ${ }^{22}$ danach von Krolop ermittelte Anspielung in einem der letzten Briefe des frühverstorbenen Autors, ${ }^{23}$ aus Zürich am 27. Januar 1837 an seine Straßburger Verlobte Wilhelmine Jaeglé:

Es ist mir heut einigermaßen innerlich wohl, ich zehre noch von gestern, die Sonne war groß und warm im reinsten Himmel - und dazu hab' ich meine Laterne gelöscht und einen edlen Menschen an die Brust gedrückt, nämlich einen kleinen Wirth, der aussieht, wie ein betrunkenes Kaninchen, und mir in seinem prächtigen Hause vor der Stadt ein großes elegantes Zimmer vermiethet hat. Edler Mensch!24

Die Mitteilung Büchners, er habe seine „Laterne gelöscht“ und sei mit einem „edlen Menschen“ bekannt geworden, paraphrasiert Pfeffels 1777 entstandenes Gedicht „Diogen“. Ihm liegt die Überlieferung zugrunde, der Kyniker Diogenes habe am hellichten Tag auf dem Markt in Athen mit der Laterne einen Menschen gesucht. Der Pfeffelsche Diogen wird zunächst bei Versuchen, „eine Gabe“ zu erbitten, mehrmals enttäuscht und zuletzt von einem Prinzen, an dessen "goldnen Wagen“ er sich hängt, mit Totschlag bedroht; jedoch, so endet das Gedicht:
Ein Sklave[,] der von Ferne stand, Sprang auf und riß mit edler Hitze
Den Alten weg, und seine Hand
Warf ihm zwei Heller in die Mütze.
Ihr Götter! rief der weise Mann,
Mehr als ein König geben kann,
Gab dieser mir; nun sterb' ich gerne.
Er weint und löschte die Laterne. ${ }^{25}$

\footnotetext{
20 Otto Friedrich Wehrhan: Umschau in Deutschland, Frankreich und der Schweiz. Leipzig 1840, S. 239.

21 Vgl. Jan-Christoph Hauschild: Georg Büchner. Biographie. Stuttgart-Weimar 1993, S. 433.

22 Georg Büchner: Werke und Briefe. Gesamtausgabe. Neue, durchgesehene Ausgabe. Hg. von Fritz Bergemann. Leipzig 1958, S. 657 (Register).

23 Vgl. Krolop: Büchner und Pfeffel (wie Anm. 3), S. 6 f.

${ }^{24}$ Georg Büchner: Briefwechsel. Marburger Ausgabe. Band 10.1. Text. Hg. von Burghard Dedner, Tilman Fischer und Gerald Funk. Darmstadt 2012 (Büchner [wie Anm. 1], S 118.

25 Poetische Versuche von Gottlieb Conrad Pfeffel. Vollständige Ausgabe in fünf Bänden (wie Anm. 15), Bd. 1, S. 136f. (Hervorhebungen H.H.)
} 
Die Erläuterungen der Marburger Büchner-Ausgabe zu der Briefstelle teilen mit, Büchner habe „vermutlich“ auf die Diogenes-Anekdote angespielt ${ }^{26}$ (worauf denn sonst?), die mit einem Zitat aus einer „Brockhaus“-Ausgabe von 1827 wiedergegeben wird. Mit der Wendung vom an die Brust gedrückten „edlen Menschen“ liege eine „verbreitete literarische Formel“ vor. ${ }^{27}$ Deren Verbreitung wäre plausibler geworden, wenn außer dem Nachweis ihres Vorkommens bei zwei minderrangigen Schriftstellern - Caroline Pichler (1769-1843) und Gustav Schilling (1805-1880) - auch Pfeffels Gedicht und mit ihm die Quelle der zu erläuternden Stelle berücksichtigt worden wäre. Fehlte in der Marburger Büchner-Arbeitsstelle ein Diogenes, um Krolops Beitrag aufzuspüren?

Der Topos vom Donnernhelfenmüssen, der aus dem letzten Druck der „Poetischen Versuche“ Pfeffels in Büchners „Woyzeck“ gelangt sein wird, ${ }^{28}$ war bereits ein Jahr nach seiner ersten Veröffentlichung in ihnen ${ }^{29}$ mit dem Gedicht „Jost“ in eine von Karl Wilhelm Ramler (1725-1798) zusammengestellte Anthologie übernommen worden. Im 1790 erschienenen dritten Band der „Fabellese“, für die der Berliner Pädagoge Fabeln und fabelähnliche Geistesprodukte seiner Zeitgenossen zusammengesucht hatte, steht es allerdings etwas abweichend. Ramler hatte sich, wie er bereits im Vorwort des ersten Bandes darlegte, generell die „Freyheit“ genommen, „einige Stellen zu ändern“,30 und erwähnte die Namen der Verfasser - darunter Pfeffel - zwar einleitend summarisch, nicht jedoch bei den ausgewählten Texten, „damit diejenigen Leser, die immer mit fremden Augen lesen, einmal versuchen mögen, ohne gutes oder böses Vorurtheil zu lesen und zu urtheilen“.31 Die Überarbeitung von „Jost“ lief darauf hinaus, dass Ramler Pfeffelsche Direktheiten oberlehrerhaft milderte. In die sozial- und kirchenkritische Tendenz des Gedichts griff er jedoch nicht ein. Mit der Ausschaltung des „Vorurtheil[s]“ wurde dem abschließenden Topos die Anonymität seiner ungewissen Herkunft wiedergegeben:

Jost.

Von seinem milden Landesvater

Durch Frohnen abgezehrt, lag Jost

Auf faulem Moos. Ein frommer Pater

Gab in dem letzten Kampf ihm Trost:

„Bald wird euch Gott vom Joch entbinden,

„Das euch auf Erden hart gedrückt;

„Die Ruhe, die Euch nie erquickt,

„Freund, werdet Ihr im Himmel finden.“

Ach! rief hier Jost verzweiflungsvoll,

Mein lieber Herr, wer kann das wissen?

26 Georg Büchner: Briefwechsel. Band 10.2. Editionsbericht, Erläuterungen. Hg. von Burghard Dedner, Tilman Fischer und Gerald Funk. Darmstadt 2012 (Büchner [wie Anm. 1]), S. 378.

27 Ebd.

28 Vgl. Anm. 15.

29 Vgl. Anm. 10.

30 Karl Wilhelm Ramlers Fabellese. Leipzig, bey Weidmanns Erben und Reich. [Erster Band] 1783, S. IV.

31 Ebd., S. VIII. 
Wir armen Bauern werden wohl

Zur Frohn' im Himmel donnern müssen. ${ }^{32}$

Auf Ramlers leicht verändernde Übernahme hatte Krolop in einem Nachtrag aufmerksam gemacht, der drei Jahre nach seiner Untersuchung „Pfeffel und Büchner" erschienen war. ${ }^{33}$ In dem Nachtrag teilte er außerdem als Zufallsfund eine Einsendung mit, die 1898 in die Münchner Satirezeitschrift „Simplicissimus“ gelangt war:

\section{Lieber Simplicissimus!}

Meine Großmutter erzählte einst folgende wahre Begebenheit:

In einem Dorfe weit oben im Riesengebirge, besucht der Pastor seine Gemeindemitglieder. Er kommt auch zu der Hütte des arnen Holzhauers „Chrischan“ (Christian), die weit abgelegen ist, tief im Walde. Chrischan ist alt und gebrechlich, durch harte, mühselige Arbeit und Entbehrungen mitgenommen. Dem klagenden Holzhauer spricht der Pastor Mut zu, tröstet ihn mit den Freuden des Jenseits und weist auf die Wiedervergeltung im Paradiese hin. Andächtig lauscht der Bekümmerte diesen Verheißungen, bis sich schließlich seinem Herzen der Seufzer entringt: „Ach, Herr Pastor, ich bin immer a ormes Luder gewest, und wenn ich emol (einmal) on a Himmel kumm, do wird der liebe Gott sagen: Chrischan, wird er sagen, du bist schwere Arbeit gewohnt, Chrischan, du kannst donnern."

cys $^{34}$

Aus seinen Funden folgerte Krolop, mit den von ihm eruierten Toposvariationen liege eine „Wanderanekdote von echter Volksläufigkeit“ vor, deren „Grundstruktur“ sich bereits abzeichne: „die Geschichte vom kleinen Mann (Bauer, Bergmann, Soldaten, Holzhauer), der aufgehört hat, ausgleichende Gerechtigkeit vom Himmel zu erwarten, weil man ihm auch dort die schwerste Arbeit aufbürden wird: donnern zu helfen. Konstant bleibt überall auch die Funktion dieser Geschichte: den Topos des himmlischen locus amoenus durch einen negativen Gegentopos aufzuheben und so der Hoffnung den Weg ins Drüben abzuschneiden. "35 Die Entwicklung dieses Anekdotenstoffes in seiner Variabilität aufzuzeigen, sei Aufgabe weiterer Forschung.

$\mathrm{Zu}$ deren Fortschritt trug 1981 Friedrich Voit im Anschluss an Krolops Studie „Pfeffel und Büchner" wesentlich bei, ${ }^{36}$ indem er eine 1781 im achten Band des Berliner „Vade Mecum für lustige Leute“ erschienene Anekdote mitteilte, von der Pfeffel zu seinem Gedicht „Jost“ inspiriert worden sei:

32 Karl Wilhelm Ramlers Fabellese. Dritter Band. Leipzig, in der Weidmannischen Buchhandlung. 1790, S. 193.

33 Kurt Krolopp[!]: „Im Himmel donnern helfen“. In: Wissenschaftliche Zeitschrift der Martin-LutherUniversität Halle-Wittenberg 12, 1963. Gesellschafts- und Sptachwissenschaftliche Reihe, H. 12, S. 1049f. - Wenn Krolops Büchner-Pfeffel-Erkenntnisse überhaupt zur Kenntnis genommen wurden, dann in der Regel aufgrund des 1963 erschienenen Beitrags, nicht aufgrund des wesentlicheren von 1960 (vgl. Anm. 3). Man erkennt das daran, dass der Verfassername als „Krolopp“ ausgewiesen wird, weil er 1963 fälschlich so angegeben wurde, wohingegen er 1960 korrekt „Krolop“ hieß. Vgl. etwa Walter Hinderer: Büchner-Kommentar zum dichterischen Werk. München 1977, S. 273.

34 Simplicissimus. Illustrierte Wochenschrift, 3. Jg., 1898, Nr. 4, S. 27.

35 Krolopp[!]: „Im Himmel donnern helfen“" (wie Anm. 33), S. 1050.

36 Friedrich Voit: „... den leven Herr Gott donnern helfen“. Zur Vorlage eines Motivs bei Pfeffel, Arnim und Büchner. In: German Life and Letters. New Series 35, 1981, No. 1, S. 1-4. 
Der arme Bauer.

Ein Bauer in Meklenburg, das heißt ein Leibeigener, ward auf dem Todbette von dem Geistlichen mit trostvollen Aussichten in die frohe Ewigkeit unterhalten. Er schien daran keinen Glauben zu haben; und da dieß den Geistlichen immer beredter und poetischer machte: sagte der Kranke endlich: „Ach Herr Pastor! he weet nich, wo't met uns Buren is, wi möten jümmer aarbeyn.“ - „Aber, lieber Jens, es giebt da gar nicht mal solche Arbeit, die euch beschwerlich seyn könnte; ihr werdet in Abrahams Schooß ruhn, und“ - „Aarbeyn möt wi gewiß: un wenn’t nix anners givt, so möt wi den leven Herr Gott donnern helpen. ${ }^{\text {" }}{ }^{37}$

Das ist der früheste bisher ermittelte Druck der Wanderanekdote. Die sie prägende Konstellation von Pfarrer, der aufs Jenseits vertröstet, und Bauer, der dem Trost widerspricht, ist schon präsent. Die Mutmaßung, der Bauer habe „keinen Glauben“, war besonders aufsässig, selbst wenn man einräumt, mit ihr sei eine obrigkeitsgenehme Distanzierung des bäuerlichen Unglaubens beabsichtigt gewesen. Dem Rezensenten, der den Achten Theil des „Vade Mecums“ in Friedrich Nicolais (1733-1811) „Allgemeiner Deutscher Bibliothek" vorstellte, missfiel zwar die Anekdote, deren Fundamentalkritik die spätaufklärerische Toleranzschwelle überschritt, er verzichtete aber darauf, das Ärgernis beim Namen zu nennen, und führte zum angeblichen „Beweis“ seines Missfallens, das auch andere Stücke des Bandes erregt hatten, lediglich deren Nummerierungen an:

Gut und angenehm! Wenn uns nur nicht auch bey diesem Theile die allgemeinen Klagen, welche schon über die vorigen Theile ergangen sind, wieder eingefallen wären, und nothwendig einfallen mußten, denn der Sammler wählt zu wenig aus, wodurch freylich manches einen Platz gefunden, das ihn nicht verdient hat. Beschuldigen ohne Beweis - - um Verzeihung! Hier ist er: Wer kann 13, 31, 40, 101, 156, 189, 249 und 251 ausstehen. ${ }^{38}$

Nr. 156 ist „Der arme Bauer“. Nicht wenige Leser werden dem Rezensenten für seine Hinweise dankbar gewesen sein. Ob diese in subversiver Absicht erfolgten, steht dahin. Jedenfalls verdient das Rezensentensigel „Sz.“ aufgrund der Rezeptionslenkung entschlüsselt zu werden: Abraham August Abendroth (1727-1786), aus Scheibenberg im Erzgebirge stammender Gerichtsprokurator in Hamburg. ${ }^{39}$ Dass derselbe Friedrich Nicolai, der das literaturkritische Berliner Zentralorgan der deutschen Spätaufklärung herausgab, auch der Kompilator des vielgelesenen „Vade Mecum für lustige Leute“ gewesen sein soll, ${ }^{40}$ leuchtet in Anbetracht der kritischen Beurteilung des achten Bandes in seinem Journal nicht ein.

37 Vade Mecum für lustige Leute enthaltend eine Sammlung angenehmer Scherze witziger Einfälle und spaßhafter kurzer Historien aus den besten Schriftstellern zusammengetragen. Achter Theil. Berlin, 1781, S. 83, Nr. 156.

38 Allgemeine deutsche Bibliothek. Des zwey und funfzigsten[!] Bandes zweytes Stück. Mit Röm. Kayserl. Königl. Preußischen, Chursächsischen und Chur-brandenburgischen allergnäd. Freyheiten. Berlin und Stettin, verlegts[!] Friedrich Nicolai, 1782, S. 606.

39 Gustav Parthey: Die Mitarbeiter an Friedrich Nicolai's Allgemeiner Deutscher Bibliothek nach ihren Namen und Zeichen in zwei Registern geordnet. Ein Beitrag zur deutschen Literaturgeschichte. Berlin 1842, S. 40 (nur Nachname); Hans Schröder, Lexikon der hamburgischen Schriftsteller bis zur Gegenwart. Bd. 1. Hamburg 1851, S. 3f.

40 Elfriede Moser-Rath: „Lustige Gesellschaft“. Schwank und Witz des 17. und 18. Jahrhunderts in kultur- und sozialgeschichtlichem Kontext. Stuttgart 1984, S. 33-35, $40 f$. 
Die Mitteilung der Anekdote im „Vade Mecum“ hatte zwei unmittelbare Aneignungen zur Folge, auf die Heinz Rölleke 1995 aufmerksam machte, allerdings ohne deren Ursprung in der Sammlung „für lustige Leute“ zu kennen. ${ }^{41}$ Er hatte - kann passieren, aber man glaubt es kaum bei diesem Gelehrten - den 1981 publizierten Fund Voits ebenso übersehen wie die 1960 erschienene Grundlegung Krolops.

Die von Rölleke ermittelten Rezipienten waren zum einen Wilhelm Heinse (1746-1803), der 1783 notierte: „Da werden wir halt donnern helfen müssen; und hier hatt ich mirs so gut gemacht." ${ }^{\text {"42 }}$

Und zum anderen ein Anonymus, der im selben Jahr in Basel in seinen „Launigte[n] Sommer-Mährchen“ ein zwei Jahre zuvor entstandenes Gedicht mitteilte:

Aussichten in die Ewigkeit eines Taglöhners. Fünfte Erzehlung. 1781.

Ein armer Gauner lag ans Grabes Rand,

Er fühlte schon des Todes Sense:

Ein kalter Angstschweiß traüfelt schon herab,

Benezt die eingeschrumpften Wangen,

Schon bricht der Augen glimmend Licht;

Er athmet schwer - und kann kaum stammeln.

Der Pfarrer tritt zur Thür hinein,

Sucht ihn zu stärken - ihn zu trösten:

Er schildert ihm die Ewigkeit.

Des Himmels reine Seligkeiten,

Wo Durst und Hunger nicht mehr quält,

Wo man die Thränen wischt von Wangen,

Und wo man seiner Werke Lohn

In ungestörter Rast geniesset[.]

„Herr Pfarrer (fiel der Bauer ein)

„Ein Mied-ling war - ich - nur auf der Erden,

„Im Schweis-se mei-nes Ange-sichts

„Errang ich je-den Bis-sen Brod-tes,

„Der mich, und Weib, und Kind erlabt,

„Hab viel ge-tra-gen, viel ge-schlep-pet:

„Im Himmel wird's nicht bes-ser gehn!

„Bald wird man un-ser-einen ken-nen,

„Und weist ihm sei-nen Po-sten an!“

Der Pfarrer lacht: „Ey Nachbar Görgen,

„Was glaubt ihr, habt ihr dort zu thun?“

Der Bau'r erwiedert ihm halb röchelnd:

„Herr - Pfar-rer, schwe-re Ar-beit g'nug,

„Werd’ traun-dort-müs-sen[!] don-nern hel-fen!“43

41 Heinz Rölleke: „Leiden sei all mein Gewinnst“. Zur Vor- und Wirkungsgeschichte eines BüchnerZitats. In: Euphorion 89, 1995, S. 330-334.

42 Wilhelm Heinse: Sämtliche Werke. Hg. von Carl Schüddekopf. Bd. 81: Aphorismen: Aus Düsseldorf. Von der italienischen Reise. Hg. von Albert Leitzmann. Leipzig 1924, S. 440.

43 Launigte Sommer-Mährchen bei langen Sommer-Tagen zu erzehlen. 1783. S. $26 f$. 
Der Titel des Gedichts spielt auf die „Aussichten in die Ewigkeit“ an, die der Züricher reformierte Pfarrer Johann Caspar Lavater (1741-1801) 1768-1778 in vier Bänden gewiesen hatte. Ihnen stellt es eine illusionslose Aussicht von unten entgegen, deren Kirchenkritik eminent ist, auch wenn sie grobschlächtig von oben herab vermittelt wird. Dass die Überschrift einen „Taglöhner“ (der von Tag zu Tag in Dienst genommen und gelöhnt wird) einführt, der erste Vers jedoch einen „Gauner" vorstellt und erst im fünfzehnten statt ihrer „der Bauer“ zu Wort kommt, kann beabsichtigt gewesen sein, um die soziale Schichtung der Desillusionierten auch unterhalb des Bauernstandes bis hinab zum Asozialen einzubeziehen. Der Verfasser des Gedichts und des Buches, in dem es steht, war dessen ebenfalls nicht genannter Basler Verleger Carl August Serini (1733-1791). ${ }^{44}$ Die „Sommer-Mährchen“ enthalten zahlreiche weitere, teils aus dem Französischen übersetzte Gedichte, die im Untertitel jeweils als „Erzählung“ bezeichnet werden. Bereits drei Jahre zuvor hatte Serini „Launigte Winter-Mährchen“, zumeist ebenfalls Übersetzungen aus dem Französischen, auf gleiche Weise kompiliert, betitelt und verlegt. ${ }^{45}$ Seine „Aussichten in die Ewigkeit eines Taglöhners“ sind die früheste bekannte Versifikation des Motivs.

Ihr folgte 1785 in Wien eine Prosaversion:

Der einfältige Peter.

Der fleissige Peter, der vorm Jahre gestorben ist, war arm und einfältig aufgewachsen. Die vielen schlechten Predigten, die er immerwährend gehört hatte, hatten ihm einen Widerwillen gegen jeden Unterricht überhaupt beygebracht. Daher war er seit 40 Jahren in keine Kirche gegangen. Einfältig also schon von Natur ... und obendrein ganz ohne Unterricht ... lesen hat er auch nie gelernt ... ward er ein Greis von 65 Jahren. Da gieng, vor seinem Tode, der Pfarrer zu ihm und redete ihm von den trostvollen Aussichten in der Ewigkeit vor. Aber Peter schien daran keinen Glauben zu haben ... Endlich sagte er: Ach, Herr Pfarrer ... ich weis nicht, wie es mit uns Bauern ist, wir müssen immer arbeiten. ... Aber, lieber Peter, sagte der Pfarrer, es giebt da keine solche Arbeit mehr, die euch beschwerlich seyn könnte; ihr werdet in Abrahams Schoos ruhen, und ...... arbeiten ... unterbrach ihn der sterbende Peter ... arbeiten müssen wir gewiß; und wenn es nichts anders giebt, so müssen wir $\mathrm{d}$ e $\mathrm{m}$ lieben Herr Gott donnern helfen.

Diese Version erschien zur erzählerischen Auflockerung eines Wirtschafts- und Haushaltungsratgebers für den österreichischen Landmann, dessen Titel die Unterweisungsbereiche detailliert anzeigt. ${ }^{46}$ „Der einfältige Peter“ steht in dem Abschnitt „Erzählungen“, der den zweiten Teil der Rubrik „Vom Ackerbau“ bildet. Die Anekdotenversion streicht die Simplizität des Bauern heraus und führt sie in erster Linie auf die „vielen

44 Zuschreibung der Universitätsbibliothek Basel im KVK. Zu Serini vgl. Karl Gauss: Die Basler Pfarrerfamilie Serini. In: Basler Zeitschrift für Geschichte und Altertumskunde 34, 1935, S. 261-287, hier S. 279f. (ohne Erwähnung der "Sommer-Mährchen“).

45 Launigte Winter-Mährchen beym Camin zu erzählen. 1780.

46 Der kluge Bauer. Oder ein Buch für den Bauer und Landmann, darinnen vom Ackerbau; von der Viehzucht; von der Haushaltungskunst; von der Gesundheit, und allerhand Hausmitteln in Krankheiten; von Lebensregeln; von allerley Merkwürdigkeiten in der Welt und aus der Natur; vom Aberglauben; von der Witterung; und man-cherley Geschichten geredet wird. Von Oesterreich Landmann. Erster Theil. Wien, 1785. Im Verlag Georg Philipp Wucherers, und gedrukt mit Weimarschen Schriften, S. 59 f. 
schlechten Predigten, die er immerwährend gehört hatte“, zurück. Diese bereits im zweiten Satz untergebrachte Kritik verstärkt der abschließende Sperrdruck. Auf die Pointe kommt es an, ist die unfromme Botschaft der Hervorhebung. Sie wird noch unbotmäßiger, wenn man in einer Anzeige der weitschweifigen Betitelung des zweiten, 1789 erschienenen (im KVK nicht nachgewiesenen) Teils des Ratgebers entdeckt, wer sich hinter dem Pseudonym „Oesterreich Landmann“ verbarg: „Der kluge Bauer. Oder ein Buch für den Bürger, Bauer und Landmann [...] Herausgegeben von Samuel Sachß, Ev. Prediger am Zlan in Stoggewoi, Mitglied der K. K. und ständischen Ackerbaugesellschaft in Kärnthen. " ${ }^{77}$ Samuel Sachß, nicht zu verwechseln mit dem nachnamensgleichen preußischen Architekten und Astronomen Salomo Sachs (1772-1855), war evangelischer Prediger in Kärnten: seit 1784 in Villach, danach in Stockenboi bei Zlan. Näheres über ihn teilte ein anonymer Beiträger im Weimarer „Archiv für die neueste Kirchengeschichte“ mit: „Er machte sich durch die Volksschrift: der kluge Bauer, ein Buch für den Bürger und Landmann 4 Thle Wien 1785-90 bekannt, und ist Kärnthen besonders sehr nützlich, hat viel Kenntnisse, so wie in seinem Hauptfache, auch in Geschichte, Dichtkunst, Oekonomie und in Religionsgegenständen sehr geläuterte Begriffe. / Durch seine Kanzelvorträge suchte er allmälig bei seiner Gemeinde die dunkle Mitternacht ihrer Religionsmeinungen aufzuhellen und Aberglauben zu tilgen, fand sich aber sehr getäuscht. Anstatt Dank und gute Früchte davon einzuärndten, erklärte ihn seine Gemeinde für einen Freigeist, die Katholiken gar für einen Gottesleugner, sein Senior Wucherer, ${ }^{48}$ für einen Heterodoxen. Dieser hielt gar in Gesellschaft mehrerer Katholischen Geistlichen Inquisition über ihn; doch er vertheidigte sich, wie es ihm, der Sache und den Inquisitoren angemessen war. Jetzt hat er keine Anfechtungen mehr, seitdem er sich bestrebt, in keiner Rücksicht auch nur die allernothwendigste Aufklärung in Religions-Sachen zu verbreiten, seine Predigten, wenn es erfordert wird, nach des selgen Habermanns und Heinrich Müllers Manier ${ }^{49}$ auszuarbeiten und sich so ganz dem Geschmack seiner Gemeinde und seines Seniors zu nähern." 50

Im selben Jahr 1785, in dem in Wien Sachß’ „Der einfältige Peter“ erschien, entstand in Colmar Pfeffels Gedicht „Jost“. Das Entstehungsjahr teilten die Inhaltsverzeichnisse der „Poetischen Versuche“ mit, in denen es 1789 erstmals erschienen war und mehrfach nachgedruckt wurde. Außerdem markierte Pfeffel darin auch diejenigen Beiträge differenziert, die literarisch angeregt worden waren: „Der * bezeichnet die Nachahmung

47 Oesterreichischer Toleranz-Bote das ist, Neueingerichteter allgemeiner Reichs-Kalender für alle Religionsgesellschaften in den kais. Kön. Erbstaaten. Auf das Jahr nach Christi Geburt 1790. [...] Herausgegeben von Jakob Friedrich Schwab, Volkslehrer zu Kosmopol. Wien, bei Georg Philipp Wucherer, k. k. priv. Groß- und Buchhändler. (Unpag. und nicht zu datierende Seite)

48 Gabriel Wucherer, evangelischer Prediger in Gnese (Gnesau) in Kärnten und Senior des Ministeriums der Protestanten in Kärnten, Bruder des berüchtigten Wiener Nachdruckers Georg Philipp Wucherer (1734-1805). (Vgl. Toshiro Uemura, Die Öffentlichkeit anhand der Wiener Broschüren zur Zeit Josephs II. Die Informationsverbreitung unter dem aufgeklärten Absolutismus. Diss. Wien 2011, S. 86.)

49 Johann Habermann (1516-1590) und Heinrich Müller (1631-1675) waren lutherische Theologen und Erbauungsschriftsteller.

50 [An.:] Etwas über die To 1 e r a n z der Katholiken gegen die Lutheraner, über den Zustand der $\mathrm{Luth}$ eris che $\mathrm{n}$ G e m e i n d e n, ihrer Geistlichen und der S c h u lan stalte $\mathrm{n}$ im Herzogthum Kä r n t h e n. In: Archiv für die neueste Kirchengeschichte. Herausgegeben von D. Heinrich Philipp Conrad Henke. Fünften Bandes erstes Stück. Weimar, im Verlage der Hofmannischen Buchhandlung. 1797, S. 109-143, hier $120 f$. 
ausländischer Fabeln, das † historische Züge und entlehnte Anecdoten, das $₫$ die umgearbeiteten Stücke. “51 "Jost“ erhielt ein $\dagger$. Von der Version im Sachß'schen Wiener Ratgeber wird Pfeffel kaum angeregt worden sein, eher von der in Serenis Basler „Sommer-Mährchen“, am ehesten von der Darbietung im Berliner „Vade Mecum“ des Jahres 1781, die bereits Sachß und Sereni inspiriert haben dürfte. Von den vorgängigen Versionen, mit denen die Pfeffelsche den abschließenden Topos gemeinsam hat, unterscheidet sie sich durch ihre poetische Qualität und eine gesellschaftskritische Schärfe, die insbesondere in der Kontraposition Josts zu den weltlichen und geistlichen Instanzen „Landesvater “ und "Pater" manifest ist. Eine Besonderheit des Gedichts liegt zudem in der Redlichkeit Pfeffels, es denjenigen seiner Stücke zuzuordnen, die durch Lektüre angeregt worden waren. Das hätten eher die anderen zugeben sollen, nicht aber ein Autor, der den überlieferten Stoff durch seine Behandlung zu einem gesellschaftskritischen Kleinkunstwerk formte.

Zwei Jahre nach der bereits vorgestellten Rezeption in Ramlers „Fabellese“ des Jahres 1790 wurde Pfeffels „Jost“ eine Aufnahme in die „Mainzer National-Zeitung“ vom 5. November 1792 zuteil, in der das Gedicht, von wenigen Druckfehlern und orthographischen Abweichungen abgesehen, zwar unverändert erschien, jedoch mit einer redaktionellen Nachbemerkung, die es im Sinn der Mainzer Jakobiner politisch aktualisierte:

Jost.

Von seinem milden Landesvater

Durch Frohnen abgezehrt, lag Jost

Auf faulem Moos. Ein frommer Pater

Gab in dem lezten Kampf ihm Trost:

Bald, sprach er, wird euch Gott entbinden

Vom Joch, das euch so hart gedrückt:

Die Ruhe die euch nie beglückt,

Freund, werdet ihr im Himmel finden.

Ach, Herr! rief Jost so dumpf und hohl,

Wie aus dem Grab, wer kann das wissen?

Wir armen Bauren werden wohl

Im Himmel frohnweis donnern müssen.

(Mein lieber Freund, hätte der Herr Pater antworten können, eure Frohnen werden bald ein Ende haben. Nächstens werden Deputirte von der Nationalversammlung aus Paris hier eintreffen, diese werden dem Dinge auf einmal das[!] Garaus machen. Wer künftig eure Dienste haben will, der muß euch bezahlen, und jetzt gilt der Bürger und Bauer so viel wie der reichste Kavalier, mit unter auch wohl noch mehr. $)^{52}$

Gedicht und Nachbemerkung erschienen ohne Verfasserangabe vierzehn Tage, nachdem sich der Mainzer Jakobinerklub, die „Gesellschaft der Freunde der Freiheit und Gleichheit“, konstituiert hatte. Ihr Organisator Georg Wilhelm Böhmer (1761-1819) war Sekretär des Generals Adam Philippe de Custine (1740-1793), unter dessen Führung die französischen Revolutionstruppen Mainz erobert hatten. Böhmer redigierte die „Main-

51 Pfeffel: Poetische Versuche (wie Anm. 15), Bd. 2, S. 199.

52 Mainzer National-Zeitung. No CLXXIV. Mondtags[!], den 5ten November, 1792. [Titelseite, unpag.] 
zer National-Zeitung“ und konzipierte die „wichtigsten Proklamationen“ Custines. ${ }^{53}$ Als der „wohl einflußreichste Mann zu Beginn der Mainzer Republik“"54 noch Privatdozent an der Philosophischen Fakultät der Universität Göttingen war, hatte er Pfeffel am 3. September 1786 in Colmar besucht, wie sich aus dessen Fremdenbuch ergibt. Der Eintrag „G. G. Böhmer“ ist vom Herausgeber als George Guillaume (Georg Wilhelm) Böhmer identifiziert worden. ${ }^{55}$ Damit dürfte gesichert sein, dass Böhmer für die Aufnahme von Pfeffels Gedicht in die „Mainzer National-Zeitung“ gesorgt und den Nachtrag verfaßt hat. Im Sinn Custines verheißt dieser den Bauern, statt sie auf das Jenseits zu verweisen, die soziale Befreiung durch die Pariser Revolutionäre und den Übergang von der Fron- in die Geldwirtschaft.

Der Hohenloher Literat Karl Julius Weber (1767-1832) hingegen machte sich und anderen in seinem im ersten Drittel des 19. Jahrhunderts entstandenen, postum veröffentlichten humoristisch-satirischen Hauptwerk „Democritos oder hinterlassene Papiere eines lachenden Philosophen“ keine Illusionen über das bäuerliche Verharrungsvermögen im Gewohnten. Mit seinem Opus reihte er sich in eine Weltbetrachtungs- und verspottungstradition ein, deren Ahnherr der antike Philosoph Demokrit von Abdera ist. In einer Reflexion Webers über Jenseitserwartungen verschiedener Völkerschaften folgt nach der Mitteilung, die „Kamtschadalen“ seien „mit Erdhütten zufrieden, nur ohne Eis, Schnee, Sümpfe und feuerspeiende Berge, vor allen Dingen aber ohne Russen und Kosaken“, die Bemerkung:

S o $n$ e g a t i v glücklich mag sich auch mancher deutsche Bauer sein Paradies denken ohne Steuereinnahmen und ohne Frohnen; doch meinte einer sie würden wenigstens dem lieben Gott helfen müssen - $\mathrm{d}$ o $\mathrm{n} n$ e $\mathrm{r} \mathrm{n}$ und b $\mathrm{l}$ i t $\mathrm{z}$ e $\mathrm{n}$ ! ${ }^{56}$

Dieselbe Redensart nutzte Weber an einer anderen Stelle seines „Democritos“ zur Illustration der Genügsamkeit des deutschen Bauern. Solange man ihn „gut und menschlich“ behandle, schütze

den Obern schon des $\mathrm{B}$ a u e r $\mathrm{n} \quad \mathrm{Ph} \mathrm{l}$ e g m a und der $\mathrm{Hang} \quad \mathrm{z} \mathrm{u} \mathrm{m} \mathrm{H} \mathrm{e} \mathrm{r} \mathrm{g} \mathrm{e} \mathrm{-}$ $\mathrm{b} r$ a c h t e n ; der Arbeit ist er so gewohnt, daß Jener glaubte, sie würden dort oben sogar d o n n e r n helfe $\mathrm{n}$ und dort unten $\mathrm{Hol} \mathrm{z}$ und $\mathrm{S} \mathrm{t} \mathrm{r}$ o h herbeischaffen müssen. ${ }^{57}$

53 Franz Dumont: Die Mainzer Republik von 179293. Studien zur Revolutionierung in Rheinhessen und der Pfalz. 2., erw. Aufl. Mainz 1993, S. 77.

54 Ebd., S. 150.

55 Gottlieb Konrad Pfeffel's Fremdenbuch mit biographischen und culturgeschichtlichen Erläuterungen hg. von H[eino] Pfannenschmid. Colmar 1892, S. 320 (Nr. 1558).

56 [1. Titelseite:] Karl Julius Webers sämmtliche Werke. Siebenter [!] Supplementband. Enthaltend Democritos siebenter[!] Band. Stuttgart. Fr. Brodhag'sche Buchhandlung. 1839. - [2. Titelseite:] Democritos oder hinterlassene Papiere eines lachenden Philosophen. Ride, si sapis. Siebenter Band. Zweite, neu durchgesehene Auflage. Einzig rechtmäßige Originalausgabe. Stuttgart. Fr. Brodhag'sche Buchhandlung. 1839, S. 214.

57 [1. Titelseite:] Carl Julius Weber's sämmtliche Werle. Sechsundzwanzigster Band. Mit königl. württembergischen Privilegium. Stuttgart. Hallberger'sche Verlagshandlung. 1840. - [2. Titelseite:] Democritos oder hinterlassene Papiere eines lachenden Philosophen. Mit Uebersetzung der aus fremden Sprachen ausgezogenen Stellen vermehrt. Ride, si sapis. Eilfter Band. Mit königl. württembergischen Privilegium. Stuttgart. Hallberger'sche Verlagshandlung. 1840, S. 59. 
„[ N ] e g a t i v glücklich“ - in diesem Bonmot ist eine Jenseitserwartung komprimiert, gegen die Weber sich als neuer Democritos hinterlistig richtet. Was ausnahmsweise - „meinte einer“, „Jener glaubte“ - gegen die bäuerliche Hoffnung auf ein eingeschränktes Paradies geäußert wird, ist der zum Weiterdenken reizende Stachel, der den Leser von ihr abbringen soll. Weber wird von Pfeffels „Jost“ angeregt worden sein. Seine Pfeffel-Kenntnis ist belegt durch ein Teilzitat des Gedichts „Charon und der Schatten“, in dem zum Schluß „Eselstreiber“ auf „Zeitungsschreiber“ aufeinander gereimt sind. ${ }^{58}$ Franz Janowitz (1892-1917) nahm es in eine kleine „Democritos“-Blütenlese auf, die er im Ersten Weltkrieg an der italienischen Front für den verehrten Karl Kraus (1874-1936) zusammenstellte. In dessen „Fackel“ erschien sie 1922 zur Erinnerung sowohl an den 1917 gefallenen Freund als auch an den „außerordentlichen, schmählich unterschätzten Karl Julius Weber“ ${ }^{59}$ Da dieser die „Dummheit der Regierten“ erkannt habe, die im Krieg für die „Mächtigen“ ihr Leben ließen, stellte Kraus in seiner Einführung zu der Auswahl heraus. Wie Webers Äußerungen über die unterwürfigen Bauern belegen, hatte er vermittels des Topos vom Donnernhelfenmüssen auch ihre „Dummheit“ in Friedenszeiten im kritischen Blick.

Die sozialkritische Funktion des Topos, die ihm seit seiner frühesten bekannten Veröffentlichung $1781 \mathrm{im}$ „Vade Mecum“ eingeschrieben ist, wird in dem Gedicht „Der Bauernbube“, das der Nürnberger Flaschnermeister Konrad Grübel (1836-1809) 1803 im dritten Band seiner „Gedichte in Nürnberger Mundart“ veröffentlichte, entschärft. Grübel ersetzte den zuvor üblichen Gegensatz zwischen Pfarrer und Bauer durch einen innerbäuerlichen Generationenkonflikt zwischen Vater und Sohn:

Der Bauernbube.

A Bauer haut an Boub'm g'hat,

An Limm'l stark und grauß,

Er häit schon zon an Reuter taugt,

Fast nauch an jed'n Mauß.

Und alli Aerbet leicht und schwer,

Döi haut er g'mahnt, wenns g'schea wär[.]

Wos niht haut offt der Voter g'sagt;

A Kerl wöi a Gaul,

Und wenn er soll an Aerbet thou,

Nau iß er ober z'faul.

Ban Fress'n und ban Böierkroug,

Dau iß er grauß und stark genoug,

58 [1. Titelseite:] Karl Julius Webers[!] sämmtliche Werke. Fünfter Supplementband. Stuttgart. Fr. Brodhag'sche Buchhandlung. 1838. - [2. Titelseite:] Democritos oder hinterlassene Papiere eines lachenden Philosophen. Ride, si sapis. Fünfter Band. Zweite, neu durchgesehene Auflage. Stuttgart. Fr. Brodhag'sche Buchhandlung. 1838, S. $347 f$.

59 Krieg. Menschheit, Zeitungen. Von Karl Julius Weber (Demokritos). In: Die Fackel. Herausgeber Karl Kraus. XXIV. Jahr, Nr. 601-607, November 1922, S. 68-73, hier S. 65f. - Teilnachdruck in: Karl Julius Weber, der Demokrit aus Hohenlohe (1767-1832). Bearb. von Martin Blümcke. Mit der Diskussion über den Büchernachdruck in der Zweiten Württembergischen Kammer im Jahre 1821. Photographien aus Hohenlohe von Roland Bauer. Marbach 1996 (Marbacher Magazin 70), S. 105. 
On Boub'n hindert alles niht,

Er häierts halt su oh;

Und mit'n in der Aerbet offt,

Dau schleigt er sih dervoh.

Deiz bäth der Voter oder flouch

Er haut halt diz scho gärbet g'noug.

Oeiz geiht in Wold die Aerbet oh;

Dau sichts diz saber aus.

Der Bou, der Voter, und der Knecht,

Sie gänga all drei naus.

Der Voter sagt; \{!] Geiht her und schaut.

Dau weiß ich öiz, wos um wörd g'haut.

Es hau't der Knecht, der Voter ah,

Der Bou fängt lang niht oh.

Er sagt; Es schneit sei Hack'n niht,

Dau wezt er immer droh.

Und wenn der Voter hih haut g'schaut

So haut er noh kann Hieb niht g'hau't.

No endlih fängt er doch su oh,

Und hau't a su a weng,

Es sicht halt ober immer su,

Er treibts nicht in die Läng.

Oeiz thout er s'Hauer untern Hout

Wöi aner der sih raff'n thout.

Er haut ka halba Stund niht g'hau't,

Oeiz soucht er scho die Rouh.

Er lahnt sih on an Bam su hih,

Und schaut in Voter zou,

Und sagt; des kohn ich niht versteih,

$\mathrm{Da}$ grod ner uns so hart soll geib.

Der Voter sagt; Wos wilst den diz?

Bist g'wiß scho wieder möid?

Du wilst halt goar ka Aerbet thou,

Dös iß des End von Löid.

In Himm'l d'rub'n rouh' mer aus,

Dau af der Welt, dau wörd nix d'raus.

Der Bube.

In Himm'l dau kummst saber oh,

Wenst halt ka Bauer wärst.

Dort wörst a mauhl scho wundern nau,

Wennst dort a Rouh begehrst.

Dort kröigt ka Bauer ah kan Louh,

Und moiss'n die härt'st Aerbet thou. 
Der Vater.

Wos wilst denn mit der Aerbet dort,

Dou kröigts a jedes gout.

Der Bube.

Will schaua, wer nau dunnern wörd,

Wenn dös ka Bauer thout,

Und in den graus'n Himm'l dau,

Wörd's scho wos z'dunnern geb'n nau. ${ }^{60}$

Die Hoffnung des fleißigen Vaters auf ein gemütliches Jenseits wird von einem faulen Sohn enttäuscht, der am Ende des Gedichts unter Reimzwang („dau“-„,nau“) versichert, der Bauer werde im Himmel zum Donnern gebraucht. Der Sohn nimmt dem Vater, der es eigentlich besser wissen müsste, die Hoffnung auf ein idyllisches Drüben, tröstet ihn aber mit seiner dortigen Unersetzbarkeit. Damit ist der Topos um seine kritische Spitze gebracht. Seine Wahrnehmung wird durch die Positionierung am Ende einer behäbig in die Länge gezogenen Darstellung bäuerlichen Lebens beeinträchtigt, die den des Dialekts unkundigen Leser zusätzlich ermüdet. Grübel scheint sie als standesbewusster Bürger einer Freien Reichsstadt von oben herab geschrieben zu haben.

Er dürfte das seinem Gedicht zugrundeliegende Motiv ebenfalls im „Vade Mecum“ kennengelernt haben, in dessen zwischen 1767 und 1792 erschienenen Bändchen zehn Anekdoten ermittelt wurden, die ihm als Quellen dienten, ${ }^{61}$ allerdings nicht diejenige zu „Der Bauernbube“. Dieses Gedicht wurde nach Grübels Tod im zweiten Band seiner 1835 punlizierten "Sämmtlichen Werke" wiedergedruckt und danach noch in deren 1857, 1873, 1884 und 1897 erfolgten Auflagen; ${ }^{62}$ seit 1835 mit lautlichen und orthographischen Änderungen („Limm’l > „Lümm'l“; „Oeiz“ > „Öiz“ etc.), die die Verständlichkeit erleichtern sollten und nicht in die Substanz eingriffen.

Da Goethe die ersten beiden, 1798 und 1800 erschienenen Bände von Grübels Gedichten in zwei wirkungsvollen Besprechungen empfohlen hatte, wird auch der dritte Band, den der Weimarer Meister nicht mehr würdigte, überregionale zeitgenössische Aufmerksamkeit erreicht haben, zumal Mundart-Lyrik durch Johann Peter Hebels gleichzeitig erschienene, ebenfalls von Goethe belobten "Allemannischen Gedichte“ (1803) en vogue war. Spätere Nachfragen sind durch die postumen Auflagen der "Sämmtlichen Werke“ bezeugt, die auch der längerfristigen Wahrnehmung des Gedichts „Der Bauernbube“ zugute gekommen sein werden.

Der darin angeschlagene gemütvolle Ton erreichte in zwei kurz nach 1840 erschienenen Anthologien seine unterste Stufe. „Herr Immerlustig“ heißt der sprechende Titel der einen durchnummerierten Sammlung. Er trägt dazu bei, dass der von ihm eingestimmte Normalleser den bitteren Hintergrund einer Anekdote überliest, die - wie schon bei Grübel - um ihren fundierenden Pfarrer-Bauer-Gegensatz gebracht ist:

60 Grübels Gedichte in Nürnberger Mundart. Drittes Bändchen. [Nürnberg: Bauer und Mann] 1803, S. 88-90.

${ }^{61}$ Friedrich Bock: Johann Konrad Grübel, ein Nürnberger Volksdichter. Festschrift zur Feier der 200. Wiederkehr seines Geburtstages. Im Auftrage des Oberbürgermeisters der Stadt Nürnberg. Nürnberg 1936, S. 101f.

62 Vgl. ebd., S. 150-162 (Nr. 43-48 der vorzüglichen Bibliographie). 
666. „Im Himmel werdet Ihr es gut haben“, sagte man zu einem Bauer, „da braucht Ihr gar nicht zu arbeiten. “ Der Bauer zweifelte und sagte: „Da wird sich auch wohl etwas finden, da werde ich müssen donnern helfen."63

Etwa gleichzeitig wurde in einem angeblich „Großen deutschen Anekdoten-Lexikon“, das in alphabetischer Reihenfolge nach Stichworten gegliedert ist, nicht nur der Pfarrer, sondern auch der Bauer aus der Anekdote entfernt. Sie ist unter dem Stichwort „Köchin“ zu einem Geträtsch zweier Köchinnen über ihre Gebieterin verharmlost, dem man zugute halten kann, dass es die Motivtradition des Diener-Herr-Konflikts ins Feministische wendete:

K ö c h i n . 1018. Zwei Köchinnen klagten sich auf dem Hausflure ihre Noth und die eine nannte ihre Herrin einen bösen Satan, der den ganzen Tagüber[!] tobe und schelte. „Na,“ rief die andere aus, „so viel is jewiß, die kommt ooch nich in'n Himmel!“ „Die nich in’n Himmel?“, erwiederte[!] jene, „die kommmt erscht recht hin! Die muß ja donnern helfen!“64

In Karl Friedrich Wilhelm Wanders (1803-1879) „Deutsches Sprichwörterlexikon“, das seit 1867 in fünf dicken Bänden herauskam, ${ }^{65}$ hat es die Wanderanekdote und mit ihr der Topos allerdings nicht geschafft. Auch nicht in Georg Büchmanns (1822-1884) „Büchmann“, der erstmals $1864^{66}$ und zuletzt $2016^{67}$ erschien. Aber in die „Geflügelten Worte“ der DDR, die 1981 in Leipzig publiziert wurden. ${ }^{68}$ Dort findet man den Topos im Schlagwortregister unter „Donnern“, im Personen- und Quellenregister unter Büchner, der mit fünfzehn Zitaten präsent ist; nicht unter Pfeffel, den zwei Zitate erinnern. Die Auszeichnung des dreiundzwanzigjährig verstorbenen Büchner mit einer, gemessen am erreichten Lebensalter, rekordverdächtigen Zahl Geflügelter Worte ist eine bisher kaum angemessen wahrgenommene Kanonisierung des Vormärzautors und des ihm zugeschriebenen Topos, der jedoch, was individualisierbare Urheberschaft und unmittelbare Wirkung anlangt, Pfeffel zuzuweisen gewesen wäre.

Als Karl Emil Franzos „Wozzeck“ 1879 erstmals unter diesem Titel herausgab, war der Topos rar geworden. Zwar wurde er in Werkausgeben Pfeffels und Grübels, die in der zweiten Jahrhunderthälfte erschienen, wieder veröffentlicht, ${ }^{69}$ aber variiert wurde die Anekdote, soweit bisher ersichtlich, lediglich in dem von Krolop aufgespürten „Simpli-

${ }^{63}$ Herr Immerlustig oder unfehlbares Mittel zur Erregung des Lachens. Eine Sammlung der neuesten Witzspiele und Anekdoten. Nebst einem Anhange der schwersten und scharfsinigsten Charaden. Mit einer Zeichnung. München, 1841 bei E. A. Fleischmann, S. 252.

64 [1. Titelseite:] Anekdoten-Lexikon. - [2. Titelseite:] Das große deutsche Anekdoten-Lexikon. Erfurt. Verlag von Fr. Bartholomäus. [Mehrere Lieferungen 184243], S. 154.

65 Deutsches Sprichwörter-Lexikon. Ein Hausschatz für das deutsche Volk. Hg. von Karl Friedrich Wilhelm Wander. 5 Bände. Leipzig 1867-1880.

66 Georg Büchmann, Geflügelte Worte. Der Citatenschatz des Deutschen Volks. Berlin 1864.

67 Der neue Büchmann. Geflügelte Worte. Der klassische Zitatenschatz gesammelt und erläutert von Georg Büchmann, fortgesetzt von Walter Robert-Tornow [u.a.]. Unveränderte Taschenbuchausgabe der 43., neu barbeiteten und aktualisierten Ausgabe von Winfried Hofmann. 5. Auflage. Berlin 2016.

68 Geflügelte Worte. Zitate, Sentenzen und Begriffe in ihrem geschichtlichen Zusammenhang. [Zusammengestellt und kommentiert von] Kurt Böttcher, Karl Heinz Berger, Kurt Krolop, Christa Zimmermann. Leipzig 1981. - 5., unveränderte Aufl. ebd. 1988.

69 In Pfeffel-Ausgaben der zweiten Jahrhunderthälfte allerdings nur in: Pfeffel: Fabeln und poetische Erzählungen. In Auswahl hg. von H[ermann] Hauff. Stuttgart 1861, Bd. 2, S. 57. 
cissimus“-Beitrag aus dem Jahr 1898. Dass bei einer systematischen Suchaktion weitere Belege gefunden würden, ist anzunehmen, doch dürfte die Erfolgsquote gering ausfallen. Eine unsystematische Recherche im WorldWideNet ergab jedenfalls keinen Treffer. Die anzunehmende Häufigkeitsschrumpfung lässt einen gegenläufigen Trend zur Fundstellendichte in der ersten Jahrhunderthälfte vermuten. Symptomatisch dürfte sein, dass dieselbe Anekdote, die 1842/43, wenn auch entstellt, in „Das große deutsche Anekdoten-Lexikon“ gelangt war, nach 1848 weder in den „Büchmann“ noch in den „Wander“ gelangte. Sollte die Verringerung des demokratischen Elans nach der Achtundvierziger-Revolution, die damalige Überlagerung des sozialen Engagements durch das nationale, des Vormärz durch den Nachmärz eine Verringerung der Topos-Häufigkeit zur Folge gehabt haben?

Diese Vermutung wird durch das Schicksal eines Gedichts von August Heinrich Hoffmann von Fallersleben (1798-1874) gestützt, mit dem der Topos bis 1848 weiterlebte:

Dort wie hier.

Mel. Was frag' ich viel nach Geld und Gut,

Wenn ich zufrieden bin?

Ich wollt', es wäre Schlafenszeit

Und alles schon vorbei.

Wir werden von der Frohnarbeit

Doch nun und nimmer frei.

Zur Arbeit sind wir hier allein,

Dort wird es auch nicht anders sein.

Der Pfarrer hört's und tröstet sie:

„Ihr lieben Kinder mein,

So etwas giebt's im Himmel nie,

Da wird nur Freude sein.

In unsers Herren Himmelreich

Ist einer nur dem andern gleich.“

Herr Pfarr, was ihr vom Himmel sprecht,

Wenn ihr's gewiß auch wißt,

Ganz gleich, das glaub' ich doch nicht recht,

Ich weiß schon, wie es ist:

Die andern trinken Wein und Bier,

Und unterdessen donnern wir.

Dieses Gedicht wurde 1842 in Hoffmanns „Deutschen Liedern aus der Schweiz“ veröffentlicht. ${ }^{70}$ Sie konnten dort unzensiert erscheinen, nachdem die zuvor, 1840/41, in Hamburg bei Campe publizierten „Unpolitischen Lieder“ des Autors in Preußen verboten worden waren und er zwar seine Professur in Breslau verloren, jedoch einen Nimbus als politisch verfolgter Schriftsteller gewonnen hatte. Die erste Auflage der neuen

70 Deutsche Lieder aus der Schweiz. Zürich und Winterthur: Druck und Verlag des literarischen Comptoirs. 1842, S. 59f. 
Gedichtsammlung kam in 5000 Exemplaren heraus. ${ }^{71} 1843,1845$ und 1848 folgten die unveränderten Auflagen zwei bis vier. In dem Gedicht entgegnet dem Geistlichen nicht mehr, wie bei Pfeffel und anderen, ein Bauer, der für seinen Stand spricht, sondern ein lyrisches Ich, das zwar ebenfalls die zur „Frohnarbeit“ gezwungenen Bauern vertritt, aber darüber hinaus alle von „Arbeit“ generell Abhängigen. Damit entspricht das lyrische Ich den veränderten gesellschaftlichen Verhältnissen des Industriezeitalters. Aber während Jost sich vom Pfarrer auf ein besseres Jenseits nicht vertrösten läßt, verhält sich das lyrische Ich in Hoffmanns Gedicht widersprüchlich. Einerseits vertraut es der Zuständigkeit des Geistlichen fürs Jenseits, wenngleich mit der Einschränkung „Ganz gleich, das glaub’ ich doch nicht recht“. Andererseits widerspricht der Minimalisierung der Ungleichheit unmittelbar danach der traditionelle Topos, der auf der Gegensätzlichkeit derjenigen, die genießen, und derjenigen, die dazu donnern, insistiert. Er bildet mit dem ShakespeareZitat der ersten beiden Verse („König Heinrich IV. Erster Teil“, V/1) einen Bezugsrahmen, der nicht nur die Erwartung einer geringen Ungleichheit unglaubwürdig macht, sondern vor allem das Gedicht als Ganzes.

Hoffmann wird den inneren Widerspruch seines Gedichts kaum beabsichtigt, aber vielleicht im Nachhinein bemerkt haben. Nach 1848 scheint er „Dort wie hier“ nicht mehr veröffentlicht zu haben, dessen kurzer Karriere die lange seines „Lied der Deutschen“ entgegensteht, das - nach einem Separatdruck 1841 - in derselben Liedersammlung wie jenes erstmals in einer Sammlung erschienen war. Während das „Lied der Deutschen“" nach 1848 unter reger Anteilnahme Hoffmanns allmählich populär wurde, ${ }^{72}$ ging „Dort wie hier“ noch zu seinen Lebzeiten unter. ${ }^{73}$ Am 11. Mai 1872 fertigte Hoffmann in Braunschweig ein Gedicht mit dem Titel „Dort und hier“, der sich lediglich durch die Konjunktion von dem dreißig Jahre zuvor publizierten unterscheidet, das sein Verfasser vielleicht vergessen hatte oder - wahrscheinlicher - vergessen machen wollte. Weit entfernt ist von den 1842 gedruckten drei Strophen die sentimentale Ichbezogenheit der vier neuen, in denen der Topos vom Donnernhelfenmüssen nicht vorkommt:

O gebt mir meine Berge wieder

Und meines Thales frisches Grün!

Dort hör' ich meines Herzens Lieder,

Dort seh' ich meine Blumen blühn.

$[\ldots]^{74}$

Die Entgegensetzung von vertröstendem Pfarrer und entgegnendem armen Mann scheint schon zu der Zeit, als Hoffmanns Gedicht „Dort wie hier“ misslang und sich die sozialen und mentalen Verhältnisse umschichteten, nicht mehr literarisch produktiv

71 Vgl. Hoffmann von Fallersleben: Mein Leben. Aufzeichnungen und Erinnerungen. Hannover 1868, Bd. 3, S. 330.

72 Vgl. vor allem Eberhard Rohse: „Das Lied der Deutschen“ in seiner politischen, literarischen und literaturwissenschaftlichen Rezeption. In: August Heinrich Hoffmann von Fallersleben 1798-1998. Festschrift zum 200. Geburtstag. Hg. von Hans-Joachim Behr, Herbert Blume und Eberhard Rohse. Bielefeld 1999 (Braunschweiger Beiträge zur deutschen Sprache und Literatur. Bd. 1), S. 51-100.

73 Eine postumes Überleben sicherte die erste Gesamtausgabe: Hoffmann von Fallersleben: Gesammelte Werke. Hg. von Heinrich Gerstenberg. Bd. 4. Berlin 1891, S. 233.

74 Ebd., Bd. 1, 1890, S. 146. 
gewesen zu sein. Sollten sie ,von unten' geändert werden, half die Einschränkung der Hoffnung auf das Jenseits nicht; die Vertröstung musste als Bewusstseinsfälschung entlarvt werden. Heinrich Heine (1797-1856), der in einem Brief an seinen Verleger Julius Campe (1792-1867) vom 1. Juni 1844 die Gedichte Hoffmanns als „Sudeleyen“ bezeichnet hatte, teilte im selben Satz mit, deren „Zeitbeziehungen“ würden in seinem Versepos „Deutschland. Ein Wintermährchen“ (1844) „trotz des poetischen Werths, reichlich überboten werden “. ${ }^{45}$ Die Andersartigkeit zeigte bereits die Benennung des neuen Heineschen Werks an, die sich von dem „Lied der Deutschen“ und dessen Auftakt „Deutschland, Deutschland über Alles“ sowie dem Hoffmannschen Haupttitel „Deutsche Lieder aus der Schweiz" abhob, in denen nicht nur „Dort wie hier“, sondern auch die spätere Nationalhymne erschienen war. ${ }^{76}$ Dass Heine im Vorwort zu seinem Versepos proklamierte, „die Dienstbarkeit bis in ihrem[!] letzten Schlupfwinkel, dem[!] Himmel, [zu] zerstören, [...] den Gott, der auf Erden im Menschen wohnt, aus seiner Erniedrigung [zu] retten " 77 konnte geradezu als Aufforderung verstanden werden, den Donnernhelfenmüssen-Topos zu entsorgen. Im ersten Caput von „Deutschland. Ein Wintermährchen“ ersetzte Heine ihn durch den Gegentopos vom „Eyapopeya vom Himmel, / Womit man einlullt, wenn es greint, / Das Volk, den großen Lümmel.“78

Gegen die Utopie vom irdischen Paradies und die Vertröstung aufs Drüben sagt Hamm in Samuel Becketts (1906-1989) „Endspiel“ (1957) ein Jahrhundert nach Heine: „Jenseits ist ... die andere Hölle. " ${ }^{79}$ Ungut vorstellbar, dass in ihr das Donnern der Armen als Höllenlärm dröhnt, deren toposhafte Zuständigkeit Woyzeck mit dem abgründigen Halbsatz eingeleitet hatte: „Unsereins ist doch einmal unseelig in der und der andern Welt“. ${ }^{80}$

Anonymus 1781, Carl August Serini 1783, Wilhelm Heinse 1783, Gottlieb Konrad Pfeffel 1785 (gedr. 1789), Samuel Sachß 1785, Karl Wilhelm Ramler 1790, Georg Wilhelm Böhmer 1792, Konrad Grübel 1803, Ludwig Achim von Arnim 1817, Georg Büchner 1836 (gedr. 1879), Karl Julius Weber 1839 und 1840, Anonymus 1840, Anonymus 1841, Hoffmann von Fallersleben 1842, Pseudonymus 1898 - das ist eine heterogene Gesellschaft genannter, ermittelter und nicht ermittelter Autoren, die den Topos vom Donnernhelfenmüssen bis zum Ende des 19. Jahrhunderts rezipiert und vermittelt haben. Auf seiner Wanderung durch die deutsche Literatur- und Kulturgeschichte hat er nicht die namhaften Literaten bevorzugt, sondern die minderrangigen, wenig oder gar nicht bekannten. Die Werke, in denen er sich zumeist aufhielt, waren nicht, sieht man von

75 Heinrich Heine: Briefe 1842-1849. Bearbeiter Fritz H. Eisner. Berlin-Paris 1972 (Heine: Säkularausgabe. Werke, Briefwechsel, Lebenszeugnisse. Hg. von den Nationalen Forschungs- und Gedenkstätten der klassischen deutschen Literatur in Weimar [später Klassik-Stiftung Weimar] und dem Centre National de la Recherche Scientifique in Paris. Weimar-Paris 1970ff. Bd. 22), S. 109.

76 Deutsche Lieder aus der Schweiz (wie Anm. 68), S. 16.

77 Deutschland. Ein Wintermährchen. Von Heinrich Heine. Hamburg. Bei Hoffmann und Campe. 1844, S. X.

78 Ebd., S. 4.

79 Samuel Beckett: Endspiel Fin de partie Endgame. Dt. Übertragung von Elmar Tophoven. Frankfurt am Main 1996, S. 41.

80 Vgl. zu Anm. 1. 
denen Pfeffels, Arnims und Büchners ab, berühmt gewesene oder gewordene der Hochliteratur, sondern weithin vergessene, zur Belehrung und Unterhaltung bestimmte der unteren literarischen Ränge. Auf die Qualität kam es weniger an. Pfeffels „Jost“ übertrifft die sonstigen den Topos transportierenden Gedichte bei weitem, Büchners Dialog-Passage alle anderen Texte. Die Pfeffelschen und Büchnerschen Versionen haben aber nicht nur die dichterische Kraft, sondern auch die sozialkritische Wucht ihres Engagements für die Armen und Geringen den sonstigen Gestaltungen voraus. Gemeinsam ist allen mehr oder weniger, dass sie die Hoffnung auf ein besseres Jenseits desillusionieren und die Aufmerksamkeit auf die diesseitige Misere richten. In Kärnten, Mecklenburg, im Riesengebirge, im Thüringisch-Sächsischen, in unbestimmten sonstigen deutschen Gebieten, in Ausgaben und Anthologien, die in Basel, Berlin, Erfurt, Frankfurt/M., Leipzig, Mainz, München, Nürnberg, Straßburg, Stuttgart und Zürich verlegt wurden, kam die Anekdote in Umlauf. Ihre hauptsächlichen Umlaufzeiten waren den Ersterscheinungsterminen zufolge die Jahre von 1781 bis 1792 und diejenigen von 1839 bis 1842, nach historischen Großereignissen gewichtet im Wesentlichen in der Vorbereitungszeit der 1789 ausbrechenden Französischen Revolution und um das Jahr 1840, auf das Friedrich Engels den Beginn der „politische[n] Bewegung der Mittelklasse oder Bourgeoisie in Deutschland“ datierte. ${ }^{81}$ Auffällig ist vor allem die Häufigkeitsabnahme nach der Achtundvieriger-Revolution in der zweiten Hälfte des 19. Jahrhunderts. Die Minderung auf die sich verändernden sozialen, politischen und mentalen Verhältnisse zurückzuführen, erscheint naheliegend, doch sollten generalisierende Schlussfolgerungen erst nach gezielten Untersuchungen zur Tradierung der Anekdote seit der Mitte des 19. Jahrhunderts gezogen werden. Dabei wären die an Erscheinensdichte zwar nachlassenden, aber doch präsenten Auswahlausgaben mit Gedichten Pfeffels und Grübels zu beachten. Und seit 1879 lag Büchners „Wozzeck“ vor.

Die Anekdote war schon vor ihrer ersten bisher eruierten Veröffentlichung 1781 bekannt. Dafür gibt es zwar keinen direkten Beleg, jedoch einen indirekten von prominenter Warte. Christoph Martin Wieland (1733-1813) erinnerte sich in einem Brief, den er zwei Monate vor seinem Tod, am 30. November 1812, aus Weimar an die Gräfin Elisabeth zu Solms-Laubach (1753-1829) schrieb, die Entgegnung des hoffnungslosen Bauern schon vor „60 Jahren“ gehört zu haben. Da er einen „ehrlichen armen Schweizerbauern“ als Gewährsmann nennt, liegt es nahe, die Kenntnis in die ersten Jahre seines Schweiz-Aufenthalts (1752-1760) zu datieren. Der Wielandsche Brief ermöglicht also, die Anekdote in einer ergreifenden Version ihrer Überlieferungsgeschichte bis in die Mitte des 18. Jahrhunderts zurückzuverfolgen. Dass er geschrieben wurde, als Wieland an seiner Übersetzung der Briefe Ciceros (106-43 v. Chr.) arbeitete, dessen geistige Nähe er „von Zeit zu Zeit spüre“, 82 dürfte Spuren in der Erinnerung hinterlassen haben:

81 Friedrich Engels: Revolution und Konterrevolution in Deutschland. In: Karl MarxFriedrich Engels: Werke. Bd. 8 (August 1851 bis März 1853). Hg. vom Institut für Marxismus-Leninismus beim ZK der SED. Berlin 1960 (MarxEngels: Werke. Hg. vom Institut für Marxismus-Leninismus beim ZK der SED. Berlin 1956ff.), S. 14.

82 Wieland an Friedrich David Gräter, 20. Dezember 1807. In: Ausgewählte Briefe von C. M. Wieland an verschiedene Freunde in den Jahren 1751. bis 1810. geschrieben, und nach der Zeitfolge geordnet. [Hg. von Heinrich Geßner und Friedrich David Gräter.] Bd. 4. Zürich 1816, S. 282. 
Sie sind zu gerecht, gegen mich nicht minder, als gegen Sich Selbst, um etwas Schlimmeres von Ihrem alten W[ieland] zu denken, als daß er, unter so vielem andern, was man mit Antritt des achtzigsten Jahrzehends verliert oder schon verloren hat, öfters in den Fall kommt, durch Zufälligkeiten aller Art, auch den gewöhnlichen Maßstab der Zeit zu verlieren, und für Wochen, Tage und Stunden anzusehen, was andre Menschen Monate, Wochen und Tage nennen. Ich besorge sehr, es ist diesem Übel nicht zu helfen, und es wird dabei bleiben bis zu meinem Übergang in die Geisterwelt, wo nach der Meinung unsrer neuen Philosophen gar kein solcher Maßstab mehr Statt findet, sondern Raum und Zeit von der allgegenwärtigen Ewigkeit auf einmal verschlungen wird, und unser Leben ein einziger untheilbarer Augenblick ist. - Ein Glaubensartickel, der, wie ich gestehen muß, bei mir so ausgemacht nicht ist. Im Gegentheil ich erröthe nicht zu bekennen, daß ich so ziem[lich] des Glaubens jenes ehrlichen armen Schweizerbauern bin, von dem mir in meiner Jugend eine Anekdote erzählt wurde, die ich nach 60 Jahren noch so gegenwärtig habe als ob ich selbst dabei gewesen wäre. Der gute Mann, der immer für einen frommen und unbescholtnen Christenmenschen passiert hatte, zeigte auf seinem Sterbebette eine so entsetzliche Furcht vor dem Tode, daß alle Zureden und Tröstungen seines Pfarrers, eines verständigen und gutmüthigen Mannes, nicht das mindeste bei ihm verfangen wollten. Endlich, da der Sterbende mit jeder Stunde, um die sein Ende näher rückte, in immer größere Angst gerieth und von keinem Trost nichts hören wollte, rief der Pfarrer endlich mit einigem Unwillen aus: aber wie ists denn auch möglich, daß ein Mann, den ich und das ganze Dorf immer für einen so guten Christen gehalten, so hartnäckig an der Barmherzigkeit Gottes und an seiner Seligkeit verzweifeln kann? Ach (versetzte der Sterbende) Ehrwürdiger Herr Pfarrer: sagt mir nichts vom Himmel. Man kennt unser einen überall; wenn ich auch in den Himmel komme, so wird mirs doch darum nicht besser gehen; ich werde immer harte Arbeiten verrichten müssen wie hier. Der Pfarrer stutzt und fragt: was für Arbeiten er denn glaube, daß man ihm im Himmel auflegen könne? - Ach, sagt der Taglöhner, mit einem tiefen Seufzer, ich werde halter müssen helfen donnern. So, denk' ich, wird's in der andern Welt auch mit mir sein. Man wird mich dort auch kennen, und ich werde halter auch für meine dortige Mitbürger Prose und Verse machen müssen wie hier. ${ }^{83}$

Dass der Topos andererseits, im 20. und frühen 21. Jahrhundert, weiterlebt, verdankt sich vor allem der bald nach 1900 einsetzenden und bis zur Gegenwart anhaltenden Popularität von Büchners „Woyzeck“ als eines Klassikers der Moderne. Zwar wurde auch Pfeffels „Jost“ in Auswahlausgaben des Dichters überliefert, die nicht unterschätzt werden sollten. Denn wenn sie sich auch im Wesentlichen an Kenner und Entdecker entlegener Literatur richteten, ${ }^{84}$ lenkten sie den Blick doch außerdem auf einen "neuen Pfeffel, einen kritischen Kopf mit einem heißen Herzen, einen Mann, dessen geistige und poetische Substanz unsere Literatur und unsere Gesellschaft auch heute gebrauchen könnten“ ${ }^{85}$ sowie auf „das kritische Potential seiner Fabeln“, in denen sich der „revolu-

83 Wielands Briefwechsel. Hg. von der Berlin-Brandenburgischen Akademie der Wissenschaften durch Siegfried Scheibe. Bd. 18: Oktober 1809 - Januar 1813. Bearb. von Klaus Gerlach u. a. Teil 1. Berlin 2004, S. 416f.

84 Gottlieb Konrad Pfeffel: Skorpion und Hirtenknabe. Fabeln, Epigramme, poetische Erzählungen und andere Prosa. Ausgewählt und mit einem Nachwort von Rudolf K. Unbescheid. Memmingen 1970 („Jost“ S. 37 u.d.T. „Jostens Zweifel“); ders.: Biographie eines Pudels und andere Satiren. Auswahl, Anmerkungen und Nachwort von Walter E. Schäfer. Ebenhausen b. München 1987 („Jost“ S. 47).

85 Ders.: „Ich aber weiß, was Freiheit ist ..... Fabeln, Poesie und Prosa. Einführung und Auswahl Hermann Ebeling. Karlsruhe 1981 (Oberrheinische Texte), S. 7 („Jost“ S. 30). 
tionär-demokratische Standort des Verfassers deutlich zu erkennen“ gebe. ${ }^{86}$ Büchners „Woyzeck“ hingegen erreichte mit den Drucken und Inszenierungen, zu denen es seit der Erstaufführung 1913 kam, mit zahlreichen Adaptionen im Schauspiel- und Musiktheater, im Film und Hörspiel ${ }^{87}$ ein weitaus größeres Publikum, das die Aufführungsberichte und Pro- und Contra-Diskussionen in den Medien vervielfältigten. Dass und wie dabei der Topos vom Donnernhelfenmüssen zitiert und instrumentalisiert wurde, wäre eine eigene Untersuchung wert. Peter Kümmel (geb. 1959) etwa schrieb 2014: „'Ich glaub, wenn wir in Himmel kämen, so müßten wir donnern helfen', heißt eine der herrlichsten Stellen des 'Woyzecks', aber man hört sie in dieser Berliner Aufführung mit Anteilnahme für die Schauspieler. Sie müssen dem Regisseur [Sebastian] Hartmann [geb. 1968] mit aller Kraft beim Donnern helfen - was der als stille Regie bezeichnet, ist doch eher laute, pompöse Herrschaft über Text und Spieler." 88

Einer, der den Topos gegenwärtig am Leben hält, ist Martin Lüdke (geb. 1943). Zu Annegret Helds (geb. 1962) in der Gegenwart angesiedelten Roman „Die Baumfresserin“ (1999) schrieb er in einer Besprechung: „Diese Figuren dürfen wie Büchners Woyzeck nur darauf hoffen, dass sie dereinst, wenn sie in den Himmel kommen sollten, noch beim Donnern helfen müssen“ 89 Über „Armut ist ein brennend Hemd“ (2015), den zuletzt erschienenen Roman der Autorin, äußerte Lüdke wiederum in einer Besprechung: „Man spürt aber auch, dass sie von Menschen schreibt, die allesamt wie Büchners Woyzeck von sich sagen können, wenn sie dereinst einmal in den Himmel kommen sollten, dann doch nur, um beim Donnern zu helfen“.90 Und in Lüdkes Laudatio zur Verleihung des Preises der Renate-Chotjewitz-Häfner-Stiftung 2018 an Annegret Held heißt es einleitend in einer Erinnerung des Laudators an einen Klassenkameraden in der Grundschule von Apolda, ein Flüchtlingskind armer Leute:

Dieser Krehahn hat bis heute viele Verwandte, etwa Woyzeck, Georg Büchners Woyzeck, der von sich meinte, dass Leute wie er, sollten sie dereinst in den Himmel kommen, dann allein deshalb, um beim Donnern zu helfen. Man muss hier nicht von den „Verdammten dieser Erde“ sprechen. Nein, es ist nur traurig. Dass Kinder wie Erich Krehahn über nützliche, ja notwendige Dinge sich derartig freuen können, das könnte nachdenklich machen. Auch im Westerwald hat Krehahn Verwandte. [... $]^{91}$

So wächst Woyzecks Stammbaum bis in die Gegenwart. Aber es fällt auf, dass der Donnernhelfenmüssen-Topos weder in „Die Baumfresserin“ noch in „Armut ist ein brennend Hemd“ vorkommt. In letzterem Roman wird Woyzecks weitläufige hessen-

86 Ders.: Politishe Fabeln und Erzählungen in Versen. Ausgewählt undmit einem Nachwort versehen von Helmut Popp. Nördlingen 1987, S. 2 („Jost“ S. 82).

87 Vgl. Dietmar Goltschnigg (Hg.), Georg Büchner und die Moderne. Texte, Analysen, Kommentar. 3 Bde. Berlin 2001-2004.

88 „Jeder Mensch ist ein leuchtender Abgrund.“ Auf deutschen Bühnen wird das Böse so schön zelebriert, dass man das Gute nicht vermisst: unterwegs auf blutiger Spur mit Woyzeck in Berlin und Charles Manson in Hamburg. In: Die Zeit, 9.10.2014, Nr. 42 (online).

89 Martin Lüdke: Im Himmel, um beim Donnern zu helfen. Annegret Helds erstaunlicher Roman über den Reichtum in engen Verhältnissen. In: Die Zeit, 2.12.1999, Nr. 49 (online).

90 Ders.: Annegret Helds Roman „Die Armut ist ein brennend Hemd“. Gott beim Donnern helfen. In: Tagesspiegel, 20.12.2015 (online).

91 Ders.: Eine Lobrede auf Annegret Held. „Dieses Land aus Wind, Nebel und Schnee“. In: www.faust-kultur .de. 
nassauische und westerwaldische Verwandtschaft in der ersten Hälfte des 19. Jahrhunderts hautnah vergegenwärtigt. Das Aufbegehren gegen die Vertröstung auf das Jenseits, das bei aller Schicksalsergebenheit in den Worten des Bauern liegt, der in Pfeffels "Jost“ seinem Pfarrer zu widersprechen wagt, ist nicht Sache der „armen Leut“, derer Annegret Held sich annimmt. Die Hoffnung auf das Jenseits ist fast das einzige, was sie haben. Sie sind so arm dran, dass ihnen auch nur der Gedanke an Widerspruch zu viel ist. Die Intensität der Darstellung des korrumpierten Lebens, in dem sie sich eingerichtet haben, schlägt beim kritischen Leser in Erschütterung um. Nur ausnahmsweise, in einer Reminiszenz an den „Hessischen Landboten“ (1834), dessen Titel und Autor nicht genannt werden, gibt Annegret Held relativ deutlich zu erkennen, dass Büchner und seine sozialkritische Sicht ihrem Roman immanent sind:

Es war nicht recht, daß die Landgänger und Markt- und Kiezenleute jetzt immer diese Schriften mitbrachten, wo sie den lieben Herzog [Adolph von Nassau, reg. 1839-1866] beleidigten und beschimpften. Fine konnte noch immer nicht sehr gut lesen und schreiben, aber was auf dem Zettel gestanden hatte, das konnte sie schon begreifen. „Krieg den Palästen!“ Der das geschrieben hatte, war schon tot. Wenn man gegen den Herzog aufbegehrte und ihn beleidigte, dann musste es ja so kommen, das war die Gerechtigkeit. ${ }^{92}$

\section{Editionsphilologische Nachbemerkung}

Eine Edition obersten Ranges wie die des „Woyzeck“ im 2005 erschienenen Band 7.2 der Marburger Büchner-Ausgabe sollte sich historisch-kritisch nicht nur in der Darbietung des Textes verhalten, sondern auch bei der Kommentierung relevanter Einzelstellen, zu denen diejenige vom Donnernhelfenmüssen zweifellos gehört. ${ }^{93}$ Durch Nichtbeachtung von Forschungsleistungen, deren Titel eigentlich hätten elektrisieren müssen - „Büchner und Pfeffel“, „Im Himmel donnern helfen“ -, ist sie jedoch hinter dem vierzig Jahre zuvor erreichten Stand zurückgeblieben. Dass die einschlägigen Veröffentlichungen des Literaturhistorikers Kurt Krolop 1960 und 1963 in wissenschaftlichen Zeitschriften publiziert wurden, die aus westdeutscher Sicht etwas abseitig erschienen sein mögen, spricht nicht im geringsten gegen ihre Auffindbarkeit und Rele-

92 Annegret Held: Armut ist ein brennend Tuch. Roman. Köln 2015, S. 203.

93 Dem Lemma „wenn wir in Himmel kämen bis donnern helfen“ ist etwa eine Druckseite gewidmet (Büchner: „Woyzeck“. Marburger Ausgabe [wie Anm. 1], S. 505f.), die Belege für die Topos-Tradition sind teils vollständig wiedergegeben, teils referiert, teils verwiesen: von dem frühesten bekannten Druck im „Vade Mecum“ über die Version in den „Aussichten in die Ewigkeit eines Taglöhners“ und diejenige Pfeffels samt deren Übernahme in die „Mainzer National-Zeitung“, über Arnims „Kronenwächter“-Stelle bis zu Hoffmanns Gedicht „Dort wie hier“. Vollständig zitiert wird außer diesem nur dasjenige Pfeffels. Warum der kurze Text im „Vade Mecum“, von dem doch, soweit feststellbar, die gedruckte Tradierung ausging, nicht wiedergegeben wird, dafür aber derjenige Hoffmanns, der für Büchner ebensowenig eine Rolle spielte wie Büchners „Woyzeck“ für Hoffmann, leuchtet nicht ein. Der Verfasser der „Aussichten in die Ewigkeit eines Taglöhners“ wäre zu ermitteln gewesen. Von den „Poetischen Versuchen“ Pfeffels hätte außer der ersten Auflage die Büchner (nach damaliger Kenntnis) zeitlich am nächsten liegende genannt werden sollen, und es wäre zudem angebracht gewesen, auf den Nachdruck in der „Mainzer National-Zeitung“ nicht nur mit Dank für Walter Grabs (1919-2000) Fingerzeig zu verweisen, sondern vor allem darauf, dass auf ihn bereits 1971 Hans-Werner Engels (1941-2010) hingewiesen hatte (H.-W. E.: Gedichte und Lieder deutscher Jakobiner. Stuttgart 1971, S. 187), der auch auf Krolops 1963 erschienenen Beitrag aufmerksam machte (nicht auf den von 1960). Wäre zudem die Wiedergabe in der „Mainzer National-Zeitung“ eingesehen worden, würde auch Hoffmanns redaktionelle Nachbemerkung aufgefallen sein, auf die Engels nicht verwiesen hatte. 
vanz. Anderen Forschungen zu Büchner ${ }^{94}$ und auch zu Pfeffel ${ }^{95}$ sind sie nicht entgangen, und die Marburger Büchner-Ausgabe hätte nicht nur im „Woyzeck“-Kommentar von ihnen profitieren können. Wären Krolops Untersuchungen bei der Kommentierung des Donnernhelfenmüssen-Lemmas berücksichtigt worden, hätte die Aneinanderreihung auf unterschiedliche Weise angeführter Belegstellen in deren Wertung als Transformationen einer Wanderanekdote eingeordnet werden können, deren „Grundstruktur" und „Funktion“ sich, wie eingangs dieses Beitrags zitiert, schon lange vor Erscheinen des Marburger „Woyzeck“-Kommentars „klar abzeichnet[en]“.

\section{RESUMÉ}

Tato studie, jež navazuje na dvě publikace literárního kritika Kurta Krolopa z let 1960 a 1963, je analýzou percepce a variace toposu „pomoci v nebi hřmít“. V centru její pozornosti je literární útvar, který se v německém kulturním okruhu označuje jako „Wanderanekdote“ a který napomáhal šiření tohoto toposu v celé německé literární, resp. kulturní historii od 18. století až do současnosti. Společným rysem většiny verzí toposu, $\mathrm{z}$ nichž mnohým je zde pozornost věnována vůbec poprvé, je změna perspektivy „zdola“: Naději na lepší život na onom světě střídá deziluze, do popředí se dostává bída pozemského života. Historizující a systematizující analýza se zaměřuje na rekonstrukci prostředí, z něhož vzešla vrcholná literární díla, kterými jsou báseň „Jost“ (1789) Konrada Pfeffela a fragment dramatu „Woyzeck“ Georga Büchnera (1836).

Dr. phil. Heinz Härtl

Klassik Stiftung Weimar

haertlh@t-online.de

94 Vgl. außer Voit (Anm. 36) vor allem Henri Poschmanns Monographie: Georg Büchner. Dichter der Revolution und Revolution der Dichtung. Berlin-Weimar 1985, S. 338 (Hinweis auf beide Beiträge Krolops) sowie die Poschmannsche Edition im Deutschen Klassiker Verlag: Georg Büchner: Dichtungen. Hg. von H. P. unter Mitarbeit von Rosemarie Poschmann. Frankfurt/M. 2002, S. $255 f$.

95 Vgl.: Zwischen Direktorium und Empire. Die Briefe Gottlieb Konrad Pfeffels an Johann Gottfried Schweighäuser (1795-1808). Aus den Handschriften hg. von Wilhelm Kühlmann und Walter Ernst Schäfer. Heidelberg 1992, S. 266; Hermann Wiegand: Gottlieb Konrad Pfeffel als Epigrammatiker. In: Gottlieb Konrad Pfeffel (1736-1809). Signaturen der Spätaufklärung am Oberrhein (wie Anm. 18), S. 114. 